\title{
Fabrication and Comparative Study on the Mechanical Properties of Epoxy based Polymer Composites with Coconut Shell Powder and Rice Husk Powder as Filler Materials
}

\author{
D Soumyalata ${ }^{1}$, Adarsh B ${ }^{2}$, Ajas Latheef ${ }^{3}$, Ashish John Mathew ${ }^{4}$, Thoufeek T S \\ ${ }^{1}$ Associate Professor, \\ ${ }^{2345}$ Student \\ Mechanical Department, \\ Musaliar College of Engineering and Technology, \\ Pathanamthitta
}

\begin{abstract}
In the course of recent decades, natural substances have been accepting extensive consideration as the substitute for manufactured fiber reinforcement, for example, glass in plastics. The utilization of naturally filled polymer composites has been impressively considered both from a logical and a business perspective, as these materials are fundamentally alluring appealing for their decreased ecological effect furthermore the all-around wonderful esthetic properties, mostly due to their ease, low thickness, and high-explicit properties and they are biodegradable or we can say perishable and non-rough during preparing, and so on. The current exploration work has been embraced, to investigate the capability of coconut shell powder and crop residue as specific rice husks as a fortifying material in polymer composites and to examine its impact on the mechanical conduct of the subsequent composite. So the point is to blend and creates a composite with natural filler material and to lead different mechanical tests and to analyze diverse filler material based manufactured composite.
\end{abstract}

Keywords - Natural fibres, composite, epoxy resin, density, hardness, tensile strength, flexural strength

\section{INTRODUCTION}

Epoxy-based composites are exquisite and basically flexible materials which can satisfy the requirements and plan of numerous applications. Lately, the enthusiasm for composite materials is expanding because of its points of interest when contrasted with solid metal compounds. Composites materials can be characterized as built materials that exist as a mix of at least two materials that bring about better properties. A blend of at least two materials generally gives an improvement in the properties of the final results. A wide assortment of materials exists in nature and can be artificially created, is accessible in numerous structures and shapes. Regardless of whether it is regular or engineered, the primary commitment of adding the second substituent is to lessen the use of unadulterated materials and at the same time diminished the materials costing. By one way or another in designing practice, the favors are more eluded to wanted properties of an item, contingent upon the appropriateness of its applications. Composites comprise of an irregular stage known as reinforcement and a persistent stage known as a matrix. Most composites comprise of mass material, and reinforcement or some likeness thereof, added fundamentally to build the quality and firmness of the lattice. Joining regular fillers in polymers is the principle worry in ongoing examination. The upsides of utilizing normal fillers incorporate high explicit quality and modulus, low thickness, inexhaustible nature. These materials are especially alluring for their diminished natural effect and the internationally wonderful aesthetical properties and furthermore natural particles are biodegradable and non-grating. Notwithstanding, there are a few weaknesses or disadvantages in common fillers, similar to low rigidity, low liquefying point, not reasonable for high temperature application, poor surface attachment to hydrophobic polymers, non-uniform filler sizes, corruption by dampness. Along these lines, synthetic medicines are done accordingly to change the fiber properties.

The utilization of natural substance filled polymer composites has been impressively examined both from a logical and a business perspective in the course of the most recent decades, as these materials are fundamentally luring for their diminished ecological effect and furthermore the comprehensively charming stylish properties. And furthermore some genuine factor is likewise considered as the investigation to show the issues of consuming Crop residue and furthermore the measure of air harm it is making yearly. So with respect to this issue, crop residue is likewise taken as one of the filler materials. Epoxy-based composite materials are broadly utilized in load-bearing applications, e.g., car, aviation, development, oil and gas, and marine businesses, in light of their ease, great mechanical properties, high explicit quality, super adhesiveness just as good thermal and dissolvable resistance etc.

\section{OBJECTIVES}

Organic particles like, coconut shell powder and crop residue explicitly rice husk has been taken as support for creating composites with a target to consider the mechanical conduct of the materials which will thusly assist with actualizing the composite into functional utilization.

So the main objectives of this work are as follows:

$>$ Fabrication of natural fibres filled epoxy-based composites. 
$>$ Assessment of mechanical properties of the composites, for example, rigidity (tensile strength), flexural, hardness, impact quality or impact strength, and so forth.

$>$ To build up a minimal cost effort characteristic fiber-based composite that can be utilized in designing engineering equipment and for business utilization.

\section{LITERATURE REVIEW}

Composite materials are made by consolidating at least two parts to accomplish wanted properties that couldn't be gotten with the different segments. During the most recent couple of years, a progression of works has been done to supplant the ordinary engineered fiber with common fiber composites.

Various deals with the use of common strands like banana, piassava, coconut coir, agave, as the reinforcement in a polymer grid have been done.

Pothana L. et al. [1] have researched banana fiber reinforced polyester composites and found that the ideal substance of banana fiber is $40 \%$. Mechanical properties of banana-fiberconcrete composites were explored truly and precisely by Corbiere-Nicollier et al. [2]. It was reputed that wrapping paper pulped banana fiber composite has reasonable flexural quality. Likewise, short banana fiber fortified polyester composite was concentrated by Pothan et al. [3]; the examination focused on the impact of fiber length and fiber content. The most sturdiness was found out at $30 \mathrm{~mm}$ fiber length though greatest effect quality was seen at $40 \mathrm{~mm}$ fiber length. Consolidation of $40 \%$ untreated strands gives a $20 \%$ expansion inside the toughness and a $34 \%$ increment in sway quality or tensile strength. Sapuan et al [4] considered the woven banana fiber strengthened epoxy composites demonstrated an entirely steady mechanical conduct under various stacking and speed condition. Rahul Kumar and Kausik Kumar [5] considered the mechanical conduct of wood dust fortified epoxy composite is concentrated under the variety of filler substance and speed. The test results bolster that effective manufacture of wood dust fortified epoxy composites is conceivable and that wood dust has great filler qualities as it improves the pliable and flexural properties of the polymeric resin. Luo and Netravali [6] considered the elastic and flexural properties of the green composites with various pineapple fiber content and contrasted them and the virgin resin. Sisal fiber is genuinely coarse and resolute; it has great quality, strength, and the capacity to extend, a partiality for certain dyestuff, and protection from weakening in seawater. Sisal ropes and twines are for the most part utilized for marine reason, farming, delivering, and furthermore when all is said in done mechanical use. Consequently keeping the above references we are creating composites expecting to consider the mechanical conduct of the materials.

\section{SCOPE}

The strengthening of Nano-sized inorganic particles or fillers in epoxy resin is increasing more consideration from the academicians and industrialists all around for the assembling of elite building materials and engineering materials. In any case, these inorganic particles lead to numerous issues in light of the fact that for the most part thermosets and thermoplastics are being utilized in the support and these are non-biodegradable. A significant favorable position of natural particles is that they can be effortlessly discarded toward a mind-blowing finish cycle by compositing or by the recuperation of their calorific incentive in a heater which is unimaginable in manufactured fiber, for example, for glass. And furthermore, a cellulosic fiber having upgraded properties both for auxiliary and nonstructural applications helps in the improvement of designing materials and then again keeps nature contamination free.

\section{ADVANTAGES OF EPOXY}

Epoxies have different advantages over thermoset and thermoplastics and they are as following:

- Corrosion safety and resistant

- Non-Magnetic and Non-attractive properties

- Extraordinary substance opposition

- Moderately less expensive and rich in availability

- Improved mechanical quality

- Improved fatigue strength

- Impact safe and resistance

- Extraordinary dampness obstruction

- Better electrical properties

- A long time span of usability

- Impeccable harm resistances

- Least shrinkage during restoring

- Better electrical properties

- Long shelf life

- Perfect damage tolerances

- Minimum shrinkage during curing

\section{MATERIALS AND METHODS}

\section{A. Material Selection}

Epoxy resins are generally being utilized for some propelled composites because of their excellent attachment to a wide assortment of filaments, predominant mechanical and electrical properties, and great execution at raised temperatures. In addition, they need low shrinkage upon common preparing and positive synthetic opposition or we can say good chemical resistance. So her epoxy L12 is picked as the matrix material and relating hardener 301 is been taken. L12 is a fluid, unmodified epoxy resin of medium consistency that can be utilized with different hardeners for making glass fiber reinforced composites. Hardener 301 is a low consistency room temperature relieving fluid hardener. It is usually utilized for hand lay-up applications as speedy cure at room temperature is required. Being fairly receptive, it offers a short pot life and abrupt fix at typical surrounding or generally closes temperatures. The characteristic fiber utilized in this examination is Coconut shell powder and Crop residue explicitly rice husk and the size of the powder is 150 microns (mesh size proportional to 100) 


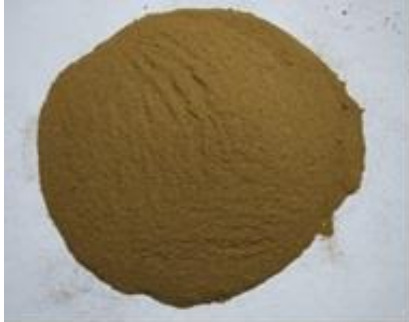

(a)

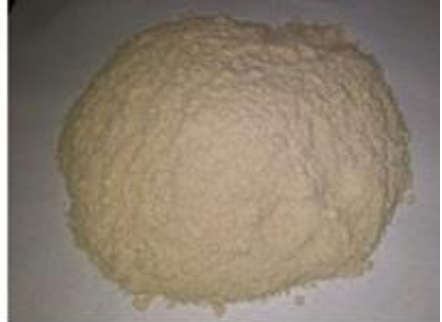

(b)
Fig.1 Reinforcement materials. (a) Coconut shell Powder (b) Rice husk powder

\section{B. Fabrication of Composites}

The form utilized for casting the composite material is an empty square shape with the components of $200 \times 200 \mathrm{~mm}$ and $6 \mathrm{~mm}$ thickness as appeared in Fig.2.The mould is produced using carbon steel. The weight percent of natural fillers is $20 \mathrm{wt}$. \% were blended in with the lattice material comprising of epoxy resin and hardener in the proportion of $4: 1$. The proportion $4: 1$ is a quick restoring matrix perfect in territories requiring a hard, artificially safe surface, (for example, tank linings). Exact estimating of the 4 to 1 proportion is significant for most extreme physical properties. The blend is mixed with the assistance of a mechanical stirrer to scatter the particles in the matrix. Extra thermal energy or heat is given to the container to limit the consistency or we can say minimize the viscosity of the blend which causes the blend to get mixed without any problem.

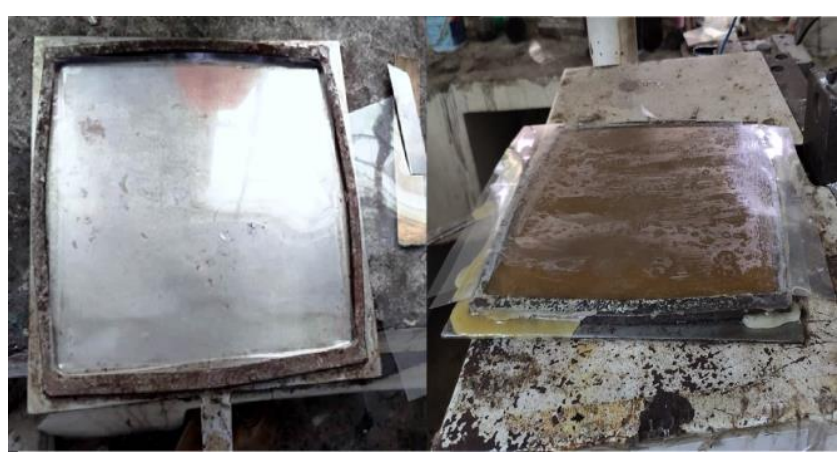

Fig. 2 Mould used for casting the composite

The hand lay-up strategy, additionally called the wet lay-up technique, is utilized for creating the composite. It is one of the most customary strategies utilized in the industry. The shape is set over an OHP sheet and the course of action is very much lubed as it is critical to isolate the composite from the form with no obstacle. Then the blend is poured into the mould and it was consistently dispersed. During pouring consideration ought to be taken to evade the arrangement of air bubbles and furthermore while applying the weight some blend comes out from the form so care to be taken while pouring. At that point, another OHP sheet was set over it. At that point, this entire arrangement was put inside a pressure forming machine called the compression moulding machine that is shown in Fig. 3 and permitted it to make do with 2 hours.

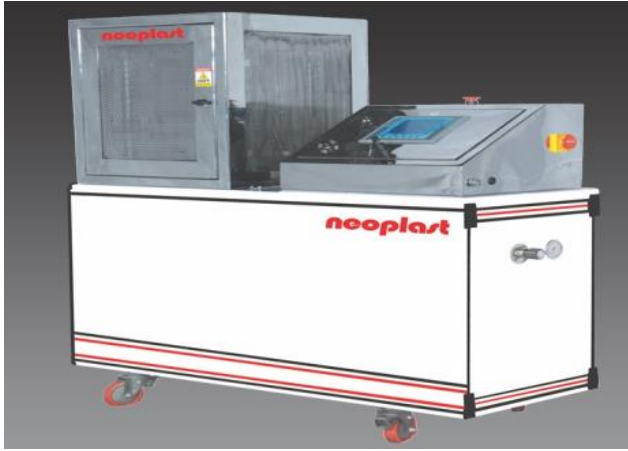

Fig. 3 Compression moulding machine

\section{Machining of Composite}

Abrasive water jet machining (AWJM) is utilized for machining the composite to get the ideal standard example or specimen for testing purposes. The benefits of AWJM incorporate no warm impact, high machining adaptability, high adaptability, little cutting power, and high profitability. Abrasive water jet machining is an all-inclusive form of water jet cutting; wherein the abrasive water jet cutting contains rough particles to build the material evacuation rate over that of water jet cutting. The abrasive utilized here is garnet and the size of the garnet particle size is 50 microns. The test arrangement and the example in the wake of cutting are shown in Fig. 4 and Fig. 5 respectively.

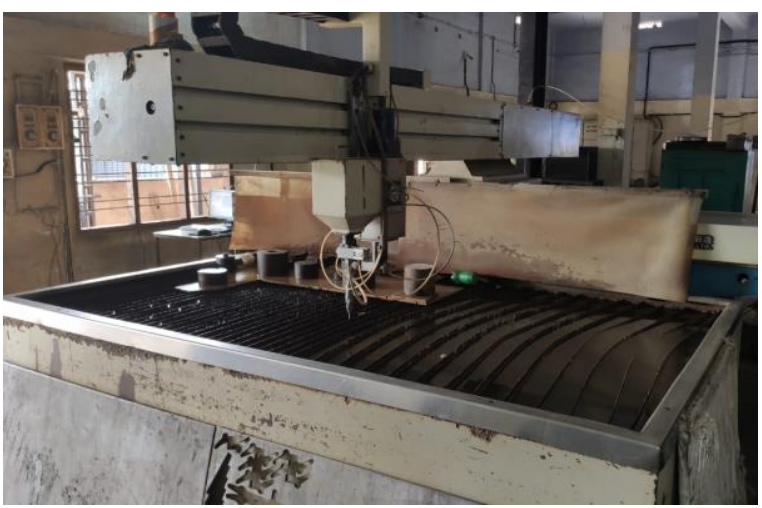

Fig. 4 Experimental setup of AWJM

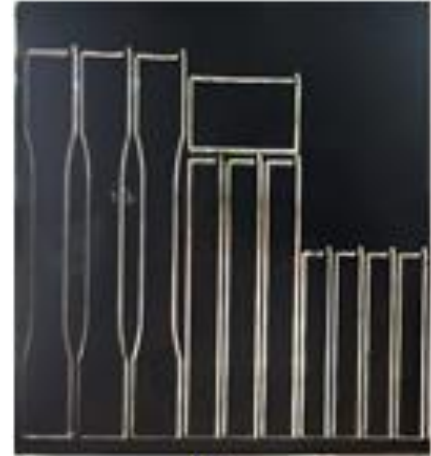

(a)

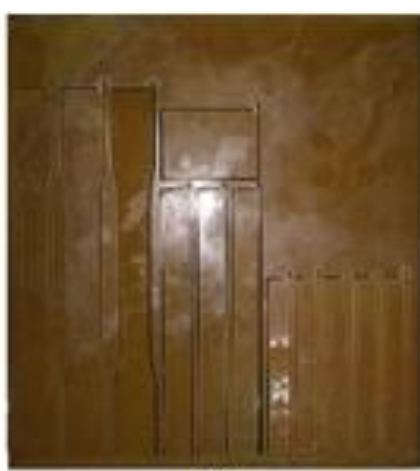

(b)
Fig. 5 Fabricated composite and machined specimen for testing (a) Coconut shell powder filled composite (b) Rice husk composite 


\section{MECHANICAL TESTING}

Here mechanical properties considered are tensile strength, flexural quality, Impact strength, Rockwell hardness test, and furthermore specific gravity is likewise considered from the composite plate and example (specimen) are machined to reasonable measurement to decide the above properties.

\section{A. Tensile Test}

The tensile test is the most ordinarily used test to assess the mechanical properties of materials. The tensile test is done on the ASTM-D-638 test standard Fig. 6 with an all-inclusive load applied at the two finishes. The test example size was $165 \mathrm{~mm}$ x $19 \mathrm{~mm}$ x $6 \mathrm{~mm}$.

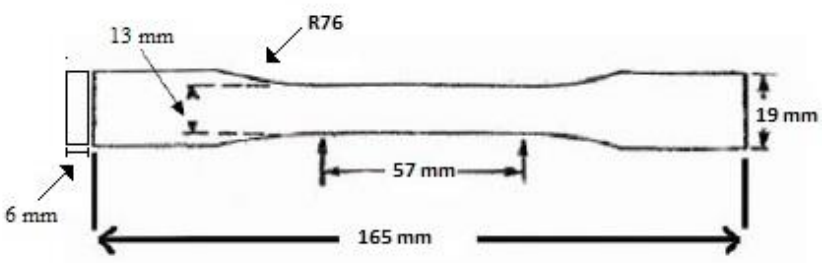

Fig. 6 Specimen dimensions for tensile test

\section{B. Flexural Test}

The flexural test examples (specimen) Fig. 7 are set up according to the ASTM D790 norms. The 3-point flexural test is the most well-known flexural test and utilized in this test for checking the bending quality of the composite examples. The test example taken is $120 \mathrm{~mm} \times 12.7 \mathrm{~mm} \times 6$ $\mathrm{mm}$. Two equal rollers underpin were utilized to help the specimen and load were given utilizing stacking nose.

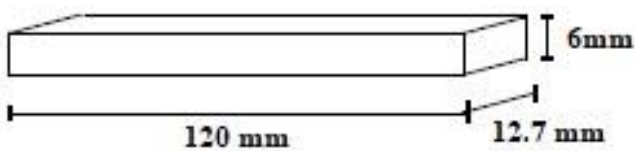

Fig. 7 Specimen dimensions for flexural test

\section{Impact Test}

Resil impact instrument is utilized in this test regularly where a bar of material is upheld as a shaft and struck at the center. The vitality which is consumed by the blow-up estimating the decrease in the swing of the pendulum contrasted and the swing with no specimen. The Impact test is completed on the ISO 180 test standard. The component of the example is taken as $80 \mathrm{~mm} \times 10 \mathrm{~mm} \times 3 \mathrm{~mm}$ as appeared in Fig. 8 .

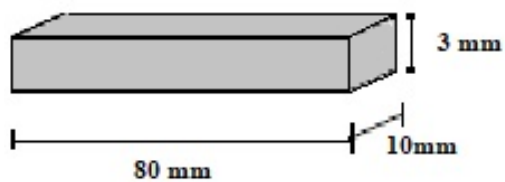

Fig. 8 Specimen dimensions for flexural test

\section{Hardness Test}

Hardness is a mechanical property that reflects the obstruction of the part or material to infiltration or penetration and scratching, it's deliberate by the hole of space and recuperation that happen once the indenter is squeezed into the surface under a tedious consistent load. Hardness can be expressed in a few different ways. There are four strategies used to express the resistance of materials to space dependent on various ideas of estimations, shore hardness, diamond pyramid hardness, Brinell hardness, and Rockwell hardness. Here shore hardness is utilized. Shore Hardness is a proportion of the opposition a material needs to indent. The Shore durometer is a gadget for estimating the hardness of a material. The ASTM D2240-00 testing standard is utilized for testing the hardness

\section{E. Specific Gravity Test}

Specific gravity alludes to the proportion of the density of an object and the reference material. Besides, the Specific gravity can let us know whether the object will sink or buoy in reference material. In addition, the reference material is water that consistently has a thickness of 1 gram for every cubic centimeter or 1 gram for every millimeter. Thickness is the mass per unit volume of a particle or material. Specific gravity is an estimation of the quantitative connection of mass of a given volume of material at $23^{\circ} \mathrm{C}$ to the indistinguishable volume of deionized water. The specific gravity is a dimensionless number. So to discover the density of the composite, it is imperative to discover its particular gravity. Any advantageous example size can be utilized for testing specific gravity.

\section{F. Water Absorption Test}

Studies had uncovered that mechanical properties, for example, strength and obstruction will fall after introduction the example for dampness, or after assimilation of the explicit amount of water and the explanation behind this, is the dampness has a job in breaking the interface between the network material and the reinforcement material and by diminishing the attachment between the lattice material and the strengthened material, or the reinforced material may retain more prominent measures of the water, causing expanding of the grid material and along these lines detachment in the framework material will be normal and the decoration of the interface in the composite material will occur and this prompts diminishing in the move of worry to the filler material and hence lead to diminishing in durability and opposition will be diminished. By drenching of the example in water, water retention, or absorption (change in mass) can be determined by the equation given by

Water absorption $(\%)=$

$$
\frac{m^{a}-m^{b}}{m^{b}} \times 100
$$

Where $\mathrm{mb}=$ mass of specimen before immersion $(\mathrm{g})$ $\mathrm{ma}=$ mass of specimen after immersion $(\mathrm{g})$

\section{RESULT AND DISCUSSION}

In this section, the result of the performed test is given and talked about reference to the point of the investigation. This 
part gives top to bottom subtleties of the venture regarding the tests performed.

A. Tensile Strength

The Tensile result shows that coconut shell reinforced composite has higher values than rice husk. (Table 1)

\section{TABLE 1. TENSILE PROPERTIES}

\begin{tabular}{|c|c|c|}
\hline Specimen & $\begin{array}{c}\text { Coconut shell } \\
(\mathbf{M P a})\end{array}$ & $\begin{array}{c}\text { Rice husk } \\
(\mathbf{M P a})\end{array}$ \\
\hline 1 & 43.6 & 16.5 \\
\hline 2 & 43.8 & 18.9 \\
\hline 3 & 44 & 20.6 \\
\hline
\end{tabular}

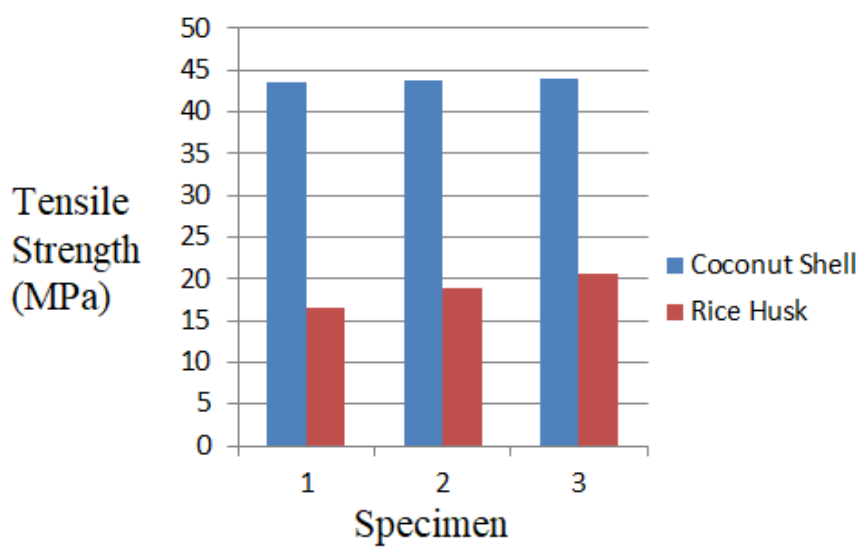

Fig. 14: Comparative graph of Coconut shell composite and rice husk composite (Tensile Strength)

A.S. Ferreira et al. [7] directed the tests on normal fiber fortified composites like sisal, ramie, curaua, jute, coir and their mechanical properties like rigidity are acquired as in appeared in table 1.6

TABLE 2: TENSILE PROPERTIES (REFERENCE)

\begin{tabular}{|c|c|c|c|c|c|}
\hline Fibre & Sisal & Ramie & Curaua & Jute & Coir \\
\hline $\begin{array}{c}\text { Tensile } \\
\text { Strength } \\
\text { (MPa) }\end{array}$ & 39 & 21 & 17 & 19 & 13 \\
\hline
\end{tabular}

\section{B. Flexural Strength}

The flexural result also shown same significant result which shows that coconut shell reinforced composite has higher values than rice husk. (Table 3)

TABLE 2: FLEXURAL PROPERTIES

\begin{tabular}{|c|c|c|}
\hline Specimen & $\begin{array}{c}\text { Coconut shell } \\
(\mathbf{M P a})\end{array}$ & $\begin{array}{c}\text { Rice husk } \\
\text { (MPa) }\end{array}$ \\
\hline 1 & 67.1 & 57.9 \\
\hline 2 & 70.5 & 59.5 \\
\hline 3 & 70.7 & 61.5 \\
\hline
\end{tabular}

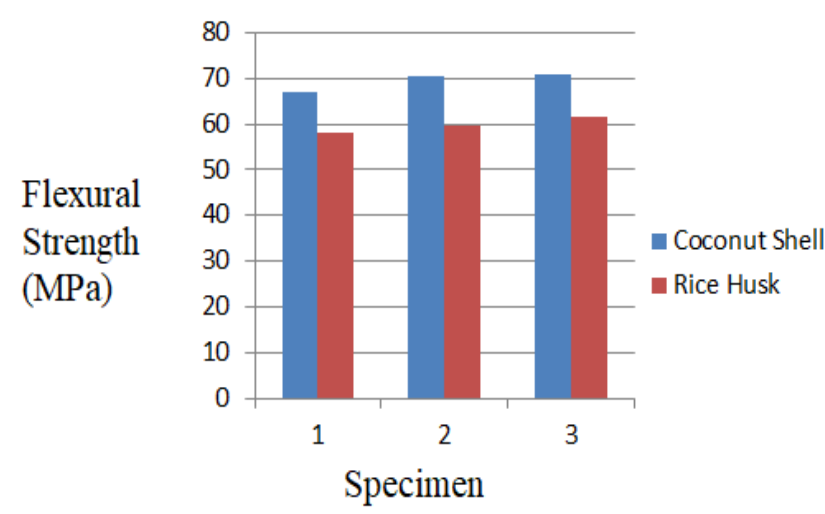

Fig. 15: Comparative graph of Coconut shell composite and rice husk composite (Flexural Strength)

\section{Impact Test}

Impact Test was conducted for all the Coconut shell powder and Rice husk epoxy composites. Table and graph shows the data of the experiment. From the experiment we can observe that Coconut shell powder composites shows better impact strength than Rice Husk epoxy composites.

TABLE 2: IMPACT STRENGTH

\begin{tabular}{|c|c|c|}
\hline Fibre & $\begin{array}{c}\text { Coconut shell } \\
\mathbf{2} \\
\left(\mathbf{K J} / \mathbf{m}^{\mathbf{2}}\right)\end{array}$ & $\begin{array}{c}\text { Rice husk } \\
\mathbf{( K J} \mathbf{2} \mathbf{m})\end{array}$ \\
\hline $\begin{array}{c}\text { Impact strength } \\
\mathbf{2} \\
(\mathbf{K J} / \mathbf{m})\end{array}$ & 10.91 & 3.25 \\
\hline
\end{tabular}

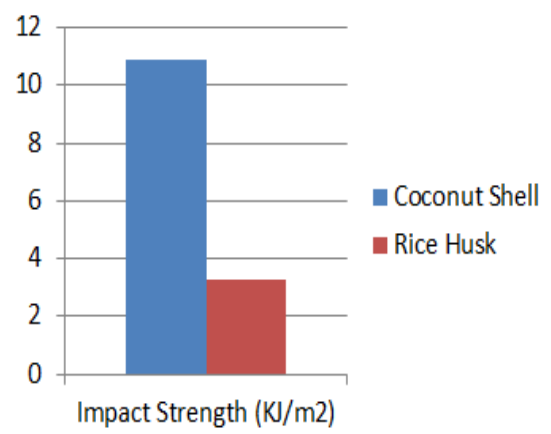

Fig. 16: Comparative graph of Coconut shell composite and rice husk composite (Impact Strength)

\section{Hardness Test}

The hardness of the composite sample analyzed by the Shore hardness which is shown in the bar graph in figure. 7

TABLE 2: HARDNESS

\begin{tabular}{|c|c|c|}
\hline Fibre & Coconut shell & Rice husk \\
\hline $\begin{array}{l}\text { Hardness } \\
\text { (Shore D) }\end{array}$ & 90 & 81 \\
\hline
\end{tabular}




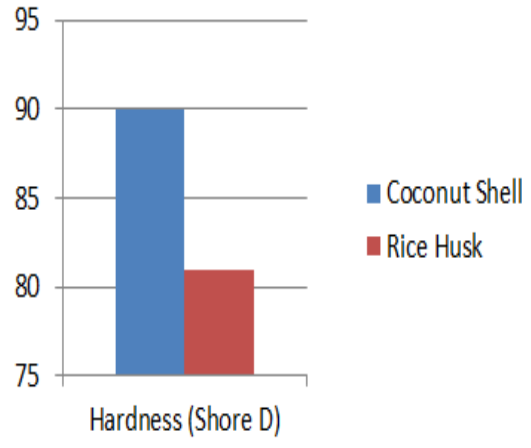

Fig. 17: Comparative graph of Coconut shell composite and rice husk composite (Hardness Number)

\section{E. Specific Gravity}

Specific gravity test was conducted for all the Coconut shell powder and Rice husk epoxy composites. Density of both composites is almost similar. Table and graph shows the data of the experiment.

\section{TABLE 4: SPECIFIC GRAVITY}

\begin{tabular}{|c|c|}
\hline Coconut shell & Rice husk \\
\hline 1.21 & 1.2 \\
\hline
\end{tabular}

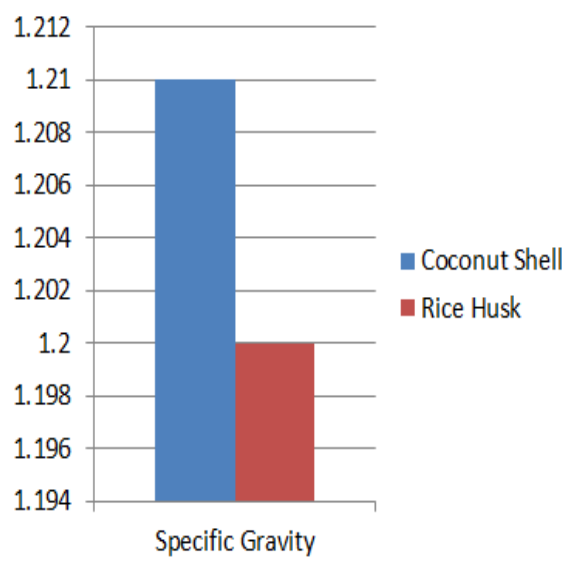

Fig. 18: Comparative graph of Coconut shell composite and rice husk composite (Specific Gravity)

\section{F. Water Absorption Test}

For the water Absorption test, the required specimen are dried in a broiler for a predefined time and temperature and afterward positioned in a desiccator to cool. Quickly after cooling the examples are gauged. The material is then raised in water at settled upon conditions, frequently $23^{\circ} \mathrm{C}$ for 24 hours or until balance. Table shows water absorption results.

TABLE 2: WATER ABSORPTION RESULTS

\begin{tabular}{|c|c|c|}
\hline \multirow{2}{*}{ Specimen } & \multicolumn{2}{|c|}{ Water absorption (\%) } \\
\cline { 2 - 3 } & Tap Water & Distilled Water \\
\hline Coconut Shell & 5.71 & 3.19 \\
\hline Rice Husk & 6.6 & 4.19 \\
\hline
\end{tabular}

\section{CONCLUSION}

The utilization of Natural fiber polymer composites loaded up with common natural fillers, in the interchange of mineral inorganic fillers. The usage of coconut shell powder in different applications has opened up new roads for the two academicians just as businesses to structure a maintainable module for some time later of coconut shell fibres. Coconut shells have been broadly utilized in composite ventures for the financial strengthening of people groups. The manufacture of coconut shell filaments based composites utilizing diverse networks has created savvy and ecoaccommodating bio composites that legitimately influencing the market estimations of coconut shells. To structure such composites exhaustive examination of crucial, mechanical, and physical properties of coconut shell fibres is essential.

The current work manages the fabrication and characterization of epoxy based polymer composites with different natural fibers as filler materials. The mechanical conduct of the composite lead to the accompanying ends, that this work shows that effective manufacture of a coconut shell powder and Rice husk strengthened epoxy composites by basic hand lay-up procedure. Relative investigation has been watched and it has been seen that Coconut shell powder is obviously superior to the rice husk strengthened epoxy composite. Tensile strength of the composite material increase with an increase in fibre, epoxy ratio. As the percentage of the coconut shell powder increase, there was a corresponding decrease in tensile strength. There is an expansion in hardness number as the proportion of fiber epoxy, and amine, epoxy expands Coconut shell filaments improve the hardness properties of the epoxy gum grid composite. This work has uncovered that coconut fiber is reasonable as a fortification material for polymer grid composites. For specific applications, the utilization of composite, as opposed to metals, has in reality brought about sparing both expense and weight. Moreover, the need for composite for lighter development materials and progressively seismic safe structures has set high accentuation on the utilization of new and propelled materials that diminishes dead weight as well as assimilates the stun and vibration through customized microstructures. Composites are currently being widely utilized for restoration and reinforcing of previous structures that must be retrofitted to make them seismic safe or to fix harm brought about by the seismic movement.

\section{REFERENCES}

[1]. Pothana L. A, Oommenb Z, and Thomas S, "Dynamic Mechanical Analysis of Banana Fibre Reinforced Polyester Composites", Composites Science and Technology, 63(2), 2003 , pp. 283-293.

[2]. Corbière-Nicollier T, Laban B. G, Lundquist L, Leterrier Y, Månson J. A. E, and Jolliet O, "Life Cycle Assessment of Biofibres Replacing Glass Fibres as Reinforcement in Plastics", Resources, Conservation and Recycling, 33(4), 2001, pp. 267 287.

[3]. Pothan L.A, Sabu T, and Neelakantan N. R, "Short Banana Fibre Reinforced Polyester Composites: Mechanical, Failure and Aging Characteristics", Journal of Reinforced Plastics and Composites, 16(8), 1997, pp. 744-765. 
[4]. Sapuan, S., Leenie A., Harimi, M., Beng, Y., 2006. Mechanical properties of woven banana fibre reinforced epoxy composites. Materials and Design 27, 689-693.

[5]. Rahul Kumar, Kausik Kumar, "Study of Mechanical Properties of Wood Dust Reinforced Epoxy Composite" Procedia Materials Science 6 (2014) $551-556$

[6]. Luo S and Netravali A. N, "Mechanical and thermal properties of environmentally friendly green composites made from pineapple leaf fibres and poly (hydroxybutyrate-co-valerate) resin", Polymer Composites, 20(3), 1999, 367-378.

[7]. $\quad$ A.S. Ferreira, K.G. Satyanarayana, F.P.D. Lopes, Selection of high strength natural fibers, Matéria (Rio J.) vol.15 no.4 Rio de Jan 2010 